\title{
Determinación "a posteriori" de las proporciones de mezcla del hormigón con áridos calizos
}

\author{
VON HEINZ PISTERS \\ Beckum Beton, $n^{\circ} 1$, enero 1972, pág. 19
}

\section{R E S U M E N}

Cuando en una obra de hormigón han de examinarse a posteriori la proporción de componentes del hormigón endurecido se precisa, frecuentemente, la determinación del contenido de cemento. Los procedimientos seguidos con este fin parten de un tratamiento del hormigón con ácido clorhídrico. En el caso de que el hormigón contenga un árido soluble en el ácido y no se disponga de él por separado, se describe detalladamente un procedimiento de identificación con una corrección sobre el contenido en dióxido de carbono del hormigón. Con arreglo a las determinaciones realizadas de este modo con el hormigón, será también posible en estos casos determinar el contenido de cemento con una precisión de, cuando menos, $\pm 10 \%$.

\section{GENERALIDADES}

Para poder resolver casos de destrucción o deterioro en construcciones de hormigón, especialmente en casos de polémica promovidas por dictámenes opuestos, así como para el control de obra, se hace frecuentemente necesario conocer también a posteriori el contenido en cemento.

Este ensayo se realiza de acuerdo con la norma DIN 52170 "Proporción de mezcla y contenido de conglomerante en morteros y hormigones endurecidos". Por este procedimiento se establece la relación ponderal en que se han mezclado conglomerante y áridos para la preparación del hormigón. Podrá, de este modo, establecerse el contenido de cemento para una relación de mezcla y una densidad aparente en el hormigón.

Para determinar la proporción de cemento y áridos, deberán separarse ambos. Con este fin, el mortero o el hormigón, se someten a tratamientos con ácido clorhídrico. Este proceso conduce a una separación del cemento (pasta de cemento) y de los áridos, cuando solamente el cemento entra en disolución, es decir, cuando es soluble en ácido clorhídrico, en tanto que los áridos permanecen insolubles (son insolubles al ácido clorhídrico). En todos los demás casos, en los que

- los áridos son parcialmente solubles con ácido clorhídrico,

- los áridos resultan totalmente solubles en ácido clorhídrico,

- o el cemento es sólo parcialmente soluble con el ácido clorhídrico, 
la norma DIN 52170 exige que, en los ensayos adicionales, se disponga, bien de áridos o bien de conglomerante por separado. Teniendo en cuenta que, casi siempre, el hormigón que ha de ser sometido a estudio tiene meses o incluso años de edad, no será posible, por lo general, encontrar los componentes del hormigón aisladamente.

La primera exigencia de la norma DIN 52170 para una completa separación del cemento y de los áridos es, por consiguiente, que aquél se disuelva totalmente en el ácido clorhídrico. Este requisito lo cumplen casi todos los cementos encuadrados en la norma DIN 1164 "Cemento portland, Cemento portland siderúrgico, Cemento de horno alto y Cemento puzolánico". Unicamente el cemento puzolánico tiene un componente en proporción notoria, insoluble en ácido clorhídrico, lo que supone un impedimento para la separación total del cemento y del árido. No obstante, el consumo del cemento puzolánico es tan reducido en la República Federal Alemana, que la necesidad de determinar la relación de mezcla en el "hormigón de cemento puzolánico" se presenta en casos contadísimos. La proporción de componentes insolubles en ácido clorhídrico de los cementos PZ, EPZ y HOZ es despreciable, quedando limitada en la norma DIN 1164 a un máximo de 3,0\% en peso. Puede partirse del hecho de que la mayor parte del cemento utilizado en la República Federal es prácticamente soluble en ácido clorhídrico en su totalidad y, por consiguiente, cumple con los requisitos de la norma DIN 52170.

Mucho más complicado es el segundo requisito de la norma DIN 52170 . Con arreglo a la misma, los áridos han de ser prácticamente insolubles en ácido clorhídrico. Esta segunda exigencia puede cumplirse relativamente con poca frecuencia, ya que todos los áridos contienen cantidades reducidas de componentes solubles en dicho ácido. La presencia incluso de un bajo porcentaje de componentes solubles en ácido clorhídrico en los áridos, influye notablemente sobre la determinación de las proporciones de mezcla, teniendo en cuenta que en el hormigón la cantidad de áridos es considerablemente mayor que la de conglomerante. Sin embargo, y según la citada norma DIN 52170 , tal y como se ha mencionado anteriormente, una determinación de áridos parcialmente o totalmente solubles sólo es posible en las condiciones prácticamente irrealizables ya citadas.

Considerando que la norma DIN 52170 es inoperante en el caso de áridos solubles, se desarrolló un procedimiento según el cual puede determinarse también la proporción de mezcla en el hormigón con una precisión de $\pm 10 \%$, cuando los áridos son total o parcialmente solubles en ácido clorhídrico, y no se dispone de áridos aisladamente para un examen a posteriori.

En la zona de Beckum se presentan áridos parcialmente solubles, al sur y este de Westfalia. Desde el punto de vista químico se trata en la fracción soluble en ácido clorhídrico de rocas carbonatadas, ricas en carbonato cálcico (caliza).

Por lo general, es cierto que se consideran rocas solubles en ácido clorhídrico, en primer término, la caliza $\left(\mathrm{CaCO}_{3}\right)$ o la magnesita $\left(\mathrm{MgCO}_{3}\right)$ o la mezcla de ambos carbonatos, p. e. dolomita $\left[\mathrm{CaMg}\left(\mathrm{CO}_{3}\right)_{2}\right.$ ]. La solubilidad de otras rocas que se utilizan como áridos para el hormigón es relativamente reducida, especialmente si la acción o efecto del ácido clorhídrico no es muy intenso o perdurable. El procedimiento propuesto parte, por lo tanto, del requisito de que se trate, en el caso de árido soluble que con mayor frecuencia se presenta, de caliza $\left(\mathrm{CaCO}_{3}\right)$.

A continuación se describe, en primer lugar, el procedimiento de análisis, informándose, seguidamente de algunos de los resultados obtenidos. 


\section{PROCEDIMIENTOS DE ENSAYO}

\subsection{Fundamento químico del método}

El carbonato de calcio $\left(\mathrm{CaCO}_{3}\right)$ consiste en, aproximadamente, un $44 \%$ de dióxido de carbono $\left(\mathrm{CO}_{2}\right)$ y un $56 \%$ de óxido cálcico $(\mathrm{CaO})$. Si un hormigón contiene, en parte o en su totalidad, $\mathrm{CaCO}_{3}$ como árido, éste se disolverá en ácido clorhídrico. Por consiguiente, el componente soluble en ácido clorhídrico de los áridos aparecería como conglomerante de acuerdo con el método convencional de cálculo de las dosificaciones.

En los áridos calizos únicamente será posible una corrección o rectificación de los áridos determinados por medios químicos (residuo insoluble en ácido clorhídrico) si se utiliza el contenido de dióxido de carbono $\left(\mathrm{CO}_{2}\right)$ de un hormigón como "molécula-guía", por decirlo así, para determinar el contenido en caliza. Se puede convertir el contenido de $\mathrm{CO}_{2}$ del hormigón en corbonato de calcio $\left(\mathrm{CaCO}_{3}\right)$ del siguiente modo:

$$
\frac{\% \mathrm{CO}_{2} \times 100}{44}=\% \mathrm{CO}_{2} \times 2,27=\% \mathrm{CaCO}_{3} .
$$

Ha de tenerse en cuenta que el cemento, según la norma DIN 1164, puede contener hasta un 2,5\% de $\mathrm{CO}_{2}$, y que el hormigón admite durante las operaciones de preparación para su análisis químico (desmenuzamiento, secado) algo más de $\mathrm{CO}_{2}$. Estas fracciones deben tenerse presentes.

Por estas razones, del contenido de $\mathrm{CO}_{2}$ del hormigón, determinado analíticamente, se descuenta un 0,3\% estimado por la experiencia. Por otra parte, el hormigón puede haber absorbido anteriormente alguna cantidad de $\mathrm{CO}_{2}$ de la atmósfera. Este proceso, conocido como carbonatación, tiene lugar en la superficie del hormigón. Para los análisis o ensayos descritos a continuación debe recurrirse exclusivamente a hormigón sin carbonatar. Por consiguiente, deberán eliminarse las zonas marginales de las muestras ya carbonatadas (véase también el apartado 2.4).

Cuando la caliza contiene, además de $\mathrm{CaCO}_{3}$, carbonato magnésico $\left(\mathrm{MgCO}_{3}\right)$, en pequeña proporción puede seguir considerándose un factor de conversión de $2,27 \times \mathrm{CO}_{2}$. Este factor se reduce cuando la porción de $\mathrm{MgCO}_{3}$ aumenta, como es el caso de la dolomita $\left[\mathrm{CaMg}\left(\mathrm{CO}_{3}\right)_{2}\right]$ con una relación molar de $1: 1$, con lo que tendremos:

$$
\frac{\% \mathrm{CO}_{2} \times 184,4}{88}=\% \mathrm{CO}_{2} \times 2,10=\% \text { dolomita. }
$$

La reducción o disminución del factor de 2,27 a 2,10 supone un 7,5 \% y da lugar, al no ser tenido en cuenta en el cálculo de las relaciones de mezcla, a un error apreciable. Normalmente, puede analizarse la composición mineralógica de los áridos del hormigón. De lo contrario, será preciso analizar un grano grueso del árido, con el fin de determinar su composición química para tener en cuenta el contenido de $\mathrm{MgCO}_{3}$.

Una vez desmenuzado y secado a $105^{\circ} \mathrm{C}$, se determina el contenido de $\mathrm{CO}_{2}$ (en $\%$ ) del grano de árido. El factor de reducción del $\mathrm{CO}_{2}$ del árido soluble que ha de establecerse será:

$$
\text { Factor }=\frac{100}{\% \mathrm{CO}_{2}}
$$




\subsection{Determinaciones químicas y físicas}

En el hormigón se determinan:

- Pérdida por calcinación y contenido de dióxido de carbono.

- Residuo insoluble en ácido clorhídrico.

- Densidad aparente del hormigón.

La "pérdida por calcinación" sirve para determinar el contenido de agua, que continúa existiendo en el hormigón tras un secado a una temperatura de $105^{\circ} \mathrm{C}$.

El agua se designará como "agua combinada", sin tener en cuenta si se trata de agua química o físicamente ligada.

Al mismo tiempo, en la pérdida por calcinación se incluye el $\mathrm{CO}_{2}$. La pérdida por calcinación (que se determina mediante tratamiento hasta $1.000^{\circ} \mathrm{C} \pm 25^{\circ} \mathrm{C}$ ) supone, por consiguiente, la suma del "agua combinada" $\left(\mathrm{H}_{2} \mathrm{O}\right)$ y del dióxido de carbono $\left(\mathrm{CO}_{2}\right)$.

El dióxido de carbono se determina con el fin de calcular la roca carbonatada contenida en los áridos. Además, se requiere el porcentaje o contenido de $\mathrm{CO}_{2}$ para calcular el agua combinada:

$\%$ de pérdida por calcinación $-\% \mathrm{CO}_{2}=$ agua combinada.

El residuo insoluble en ácido habrá de determinarse para conocer el árido. Cuando la totalidad del árido es francamente insoluble (por ejemplo arena gruesa de cuarcita del Rhin), el residuo insoluble en ácido puede equipararse al contenido de árido en el hormigón. Normalmente, el contenido en $\mathrm{CO}_{2}$ de este tipo de hormigones es muy reducido.

Si los áridos son parcialmente solubles en ácido clorhídrico, se determina en primer lugar la fracción de los áridos insolubles en ácido. A este porcentaje de los áridos se le suma la parte que contiene $\mathrm{CO}_{2}$ (soluble) $\left(\% \mathrm{CO}_{2} \times 2,27=\% \mathrm{CaCO}_{3}\right) . \mathrm{Si}$ los áridos se disuelven prácticamente en su totalidad en el ácido ( $\sin$ residuo insoluble), estaremos en presencia de áridos carbonatados.

La "densidad aparente" (R) del hormigón ha de determinarse con el fin de poder calcular, por la proporción de mezcla, el contenido o porcentaje de cemento por cada $\mathrm{m}^{3}$ de hormigón. Las instrucciones para este cálculo figuran en el apartado 2.7.

\subsection{Toma y dimensiones de la muestra de hormigón}

La cantidad de material que ha de tomarse para la determinación de la proporción de mezcla, depende del tamaño máximo de los áridos. Habrá de tomarse para un:

$$
\begin{aligned}
& \text { — tamaño máximo hasta de } 30 \mathrm{~mm} \ldots \ldots \ldots \ldots \ldots \text { aproximadamente } 5 \mathrm{~kg} \text {; } \\
& \text { — tamaño máximo hasta de } 7 \mathrm{~mm} \ldots \ldots \ldots \ldots \ldots \text { aproximadamente } 3 \mathrm{~kg}, \mathrm{y}
\end{aligned}
$$

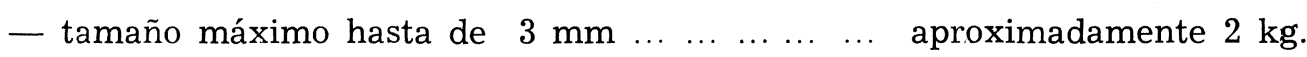

Para cada punto de una obra, en el que ha de determinarse el porcentaje de cemento, habrá de tomarse una muestra independiente. La muestra deberá guardarse herméticamente cerrada inmediatamente después de efectuada la toma. 


\subsection{Preparación de la muestra}

Se comprueba con fenolftaleína si alguna parte de la muestra está carbonatada y tiene que ser eliminada (véase el apartado 2.1.).

La muestra se desmenuza primeramente a grosso modo, si esto fuese necesario. Se toman dos o tres trozos para la determinación de la densidad aparente. El resto se desmenuza en una trituradora de laboratorio hasta un tamaño máximo de unos $2 \mathrm{~mm}$. En un separador de muestras de laboratorio se preparan a continuación, en una o dos operaciones, de 50 a $100 \mathrm{~g}$ como muestra representativa, secándose a una temperatura de $105^{\circ} \mathrm{C}$ hasta alcanzar la constancia de peso. Esta fracción se muele a continuación hasta lograr una finura para análisis $(<0,2 \mathrm{~mm})$, conservándose en un recipiente hermético. Esta preparación deberá realizarse en el tiempo más breve posible, teniendo en cuenta la absorción relativamente rápida de $\mathrm{CO}_{2}$ de la atmósfera. Lo más indicado es conservar estos finos para análisis envasados en un recipiente hermético dentro de un desecador con amianto sodado.

\subsection{Realización de los análisis}

Todas las determinaciones citadas a continuación (pérdida por calcinación, dióxido de carbono, residuo insoluble en ácido clorhídrico, densidad aparente del hormigón) deberán de realizarse por duplicado. Si los valores del análisis doble difieren en más de un $2 \%$ (relativo), se realiza un tercer ensayo de control. Los cálculos posteriores se efectúan con los valores medios de los individuales, que no difieren entre sí en más de un $2 \%$ (relativo).

\subsubsection{Pérdida por calcinación}

Un gramo de la muestra preparada de acuerdo con lo indicado en el apartado 2.4. y pesado con precisión de $0,1 \mathrm{mg}$, se introduce en un crisol y se calienta durante 10 minutos en un horno eléctrico a una temperatura de $1.000^{\circ} \mathrm{C} \pm 25^{\circ} \mathrm{C}$. Teniendo en cuenta que existe el riesgo de que el material salpique, es conveniente cubrir el crisol con una tapa. Después se enfría la muestra en un desecador a temperatura ambiente, pesándose con la misma precisión $(0,1 \mathrm{mg})$.

Cálculo:

$$
\% \text { pérdida por calcinación }=\frac{(E-A) \times 100}{E}
$$

donde:

$$
\begin{aligned}
& E=\text { peso inicial (en gramos) } \\
& A=\text { peso final (en gramos). }
\end{aligned}
$$

\subsubsection{Dióxido de carbono $\left(\mathrm{CO}_{2}\right)$}

El dióxido de carbono $\left(\mathrm{CO}_{2}\right)$ se determina de acuerdo con el procedimiento 2.2.8. del Método de análisis de cementos" (Serie de publicaciones de la industria del cemento, cuaderno 37/1970), o con arreglo a algún otro procedimiento adecuado. A continuación se describe el procedimiento 2.2.8 del "Método de análisis de cementos", así como el correspondiente aparato (fig. 1). Para producir vacío en el dispositivo se emplea una pequeña bomba de vacío o un tubo de nivel. 


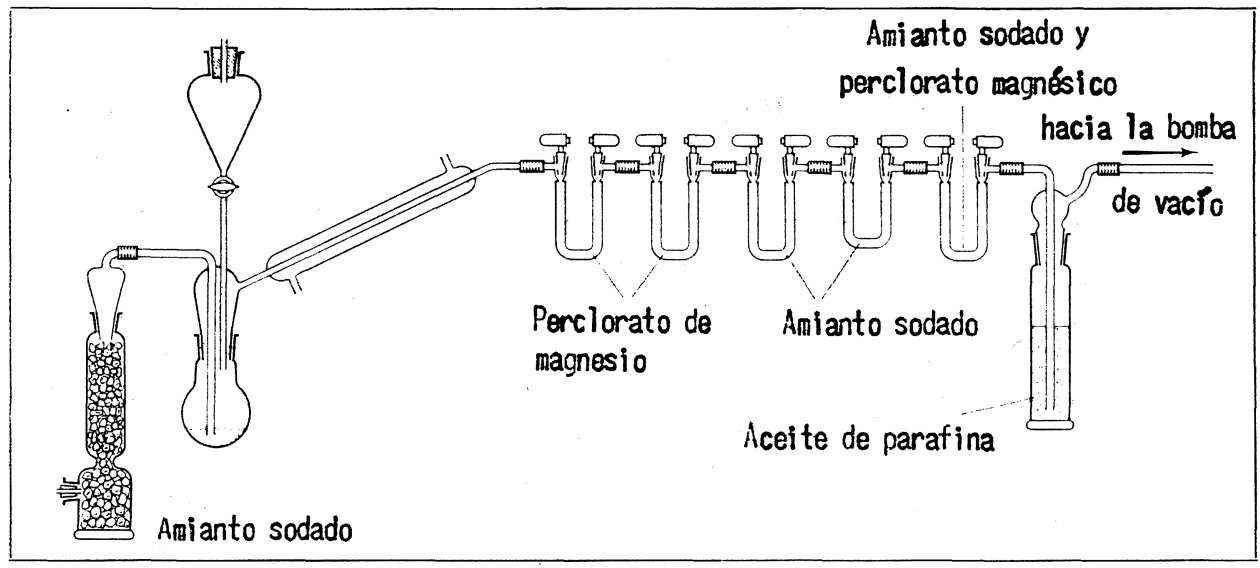

Fig. 1.-Aparato para la determinación gravimétrica del dióxido de carbono.

Reactivos:

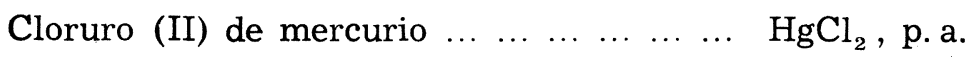

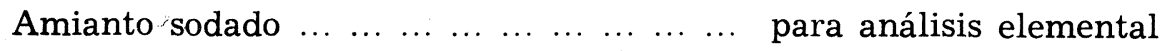

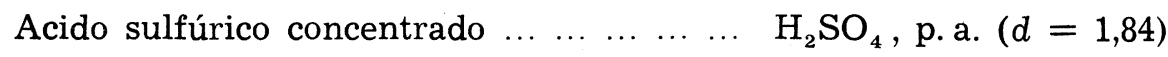

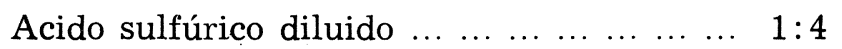

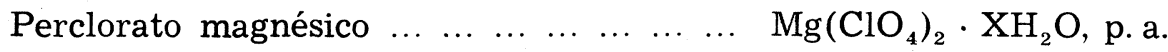

En el matraz de destilación de $100 \mathrm{ml}$ (NS 29) del aparato se pesa $1 \mathrm{~g}$ de la muestra, a 0,1 mg, preparada con arreglo al apartado 2.4., mezclándose con una punta de espátula del cloruro (II) de mercurio, ayudado con un poco de agua.

El matraz se fija herméticamente con el embudo de decantación. A continuación, y por espacio de 15 minutos, se aspira aire a través del aparato, pasando el aire aspirado, antes de penetrar en el matraz, por una columna desecadora llena de amianto sodado, con lo que queda libre de dióxido de carbono. Tras cortar la corriente de aire mediante estrangulación del tubo de conexión entre la columna de amianto sodado y el matraz de destilación con una pinza de Mohr, se cierran las llaves de paso de los dos tubos de absorción llenos de amianto sodado, retirándose dichos tubos y determinando su peso con una sensibilidad de 0,1 mg. A continuación se montan nuevamente los tubos en el aparato, y se añaden por el tubo de decantación de 25 a $30 \mathrm{ml}$ de ácido sulfúrico 1:4 en el matraz. Al proceder de este modo, deberá procurarse que un resto del ácido permanezca en el embudo de decantación como líquido de bloqueo. Después de abrir la pinza de Mohr, la corriente de aire arrastra el dióxido de carbono liberado a través del refrigerante, y los dos tubos de absorción llenos de perclorato de magnesio que sirven para el secado hacia los dos tubos de absorción llenos de amianto sodado previamente tarados. Para evitar que penetre dióxido de carbono y agua procedentes de la atmósfera, se conecta a continuación un tubo de absorción lleno de perclorato magnésico y amianto sodado. A éste se acopla un lavador de gases lleno de aceite de parafina que actúa como cuenta-burbujas. Al cabo de unos 10 minutos se calienta el contenido del matraz hasta la ebullición. Se prosigue la absorción de aire hasta que el matraz de destilación se enfríe. A continuación se cierran las llaves y se desmontan los tubos de absorción, los cuales, acto seguido, se colocan en un secador por un período de 5 minutos para estabilizar su temperatura, pesándose seguidamente con la misma sensibilidad que al principio del ensayo. 
Cálculo:

$$
\% \mathrm{CO}_{2}=-\frac{(A-B) \times 100}{E} ;
$$

donde:

$A=$ peso de los tubos de absorción, después de la absorción (en g);

$B$ =: peso de los tubos de absorción, antes de la absorción (en g);

$E=$ peso inicial de la muestra (en g).

\subsubsection{Residuo insoluble en ácido clorhídrico}

Reactivos:

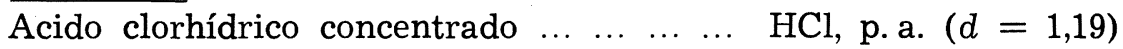

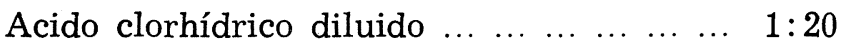

$\begin{array}{llllllllllll}\text { Cloruro sódico } & \ldots & \ldots & \ldots & \ldots & \ldots & \ldots & \ldots & \ldots & \ldots & \ldots & \mathrm{NaCl}, \mathrm{p} . \text { a. }\end{array}$

Solución de cloruro sódico $\ldots \ldots \ldots \ldots \ldots \ldots 29 \mathrm{~g}$ de cloruro de sodio se diluyen con agua hasta $1.000 \mathrm{ml}(\sim 0,5 \mathrm{~N})$

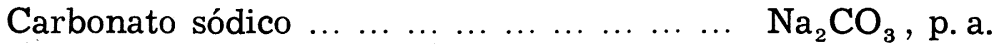

Solución de carbonato sódico $\ldots \ldots \ldots \ldots \ldots \ldots 3 \mathrm{~g}$ de carbonato sódico se diluye con agua hasta $1.000 \mathrm{ml}(\sim 1 \mathrm{~N})$

Unos $3 \mathrm{~g}$ de la muestra preparada de acuerdo con el apartado 2.4. y pesada a 0,1 $\mathrm{mg}$ se deslíen con $70 \mathrm{ml}$ de agua en un vaso de vidrio de $250 \mathrm{ml}$ (forma alta) y se mezclan con $10 \mathrm{ml}$ de ácido clorhídrico concentrado, hirviéndose durante 1 minuto. A continuación se filtra por un crisol filtrante de vidrio $1 \mathrm{G} 4$, se limpia bien el vaso de vidrio, y se lava el residuo en el crisol tres veces con solución de cloruro de sodio $(\sim 0,5 \mathrm{~N})$ caliente $\left(\sim 80^{\circ} \mathrm{C}\right)$. Para la limpieza del vaso de vidrio y para el lavado solamente podrá utilizarse una solución de cloruro sódico. El crisol deberá disponerse vacío siempre que se lave. Después se lava cinco veces con solución caliente $\left(\sim 80^{\circ} \mathrm{C}\right)$ de carbonato sódico, con el fin de disolver el ácido silícico del conglomerante que se haya producido. Acto seguido, se lava tres veces con solución caliente de cloruro sódico y, finalmente, tres veces con ácido clorhídrico diluido caliente.

A continuación se seca el crisol en una estufa a una temperatura de $105^{\circ} \pm 5^{\circ} \mathrm{C}$, hasta peso constante $(\sim 30$ minutos). El residuo se pesa a $0,1 \mathrm{mg}$, indicándose el porcentaje en función de la pesada inicial de la muestra.

Cálculo:

$$
\% \text { de residuo insoluble al ácido clorhídrico }=\frac{A \times 100}{E}
$$

donde:

$$
\begin{aligned}
& A=\text { peso final (en g) } \\
& E=\text { peso inicial (en g). }
\end{aligned}
$$

\subsubsection{Densidad aparente del hormigón}

La densidad aparente del hormigón se determina basándose en la norma DIN 52102 "Ensayo de la piedra natural; determinación de la densidad". Para ello se secan dos o más trozos de hormigón a una temperatura de $105^{\circ} \mathrm{C}$ hasta la constancia de peso, y se pesan 
(peso en estado seco $G_{\mathrm{t}}$ ); a continuación se embeben de agua las piezas que sirven para el ensayo, determinándose su peso una vez que han sido enjugadas con un paño húmedo $\left(G_{\mathrm{s}}\right)$; acto seguido se determina, con ayuda de la balanza hidróstática, el peso sumergido $\left(G_{\mathrm{u}}\right)$ de las muestras, estableciéndose la densidad con arreglo a la siguiente fórmula:

$$
R=\frac{G_{\mathrm{t}} \times 1.000}{G_{\mathrm{s}}-G_{\mathrm{u}}}\left(\mathrm{kg} / \mathrm{m}^{3}\right) .
$$

Partiendo de los valores parciales de los distintos ensayos se calcula el valor medio $R$ (en $\left.\mathrm{kg} / \mathrm{m}^{3}\right)$.

\subsection{Valoración y cálculo de las proporciones de mezcla}

La proporción de mezcla de un hormigón, que ha sido preparado total o parcialmente con áridos solubles en ácido clorhídrico, se calcula del siguiente modo, partiendo de los valores medios de los resultados obtenidos en los análisis.

\subsubsection{Agua combinada}

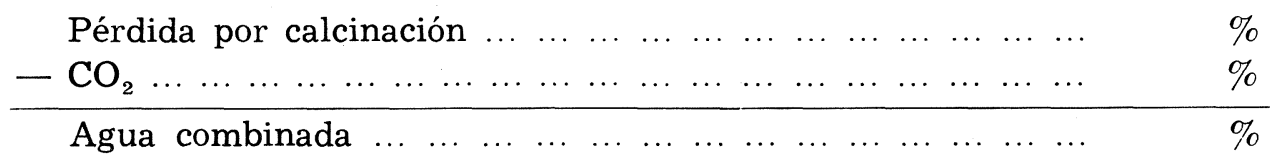

2.6.2. Caliza (carbonato cálcico) en los áridos

$\begin{array}{llllllllllllllllll}\mathrm{CO}_{2} \text { total } & \ldots & \ldots & \ldots & \ldots & \ldots & \ldots & \ldots & \ldots & \ldots & \ldots & \ldots & \ldots & \ldots & \ldots & \ldots & \ldots & \ldots\end{array}$

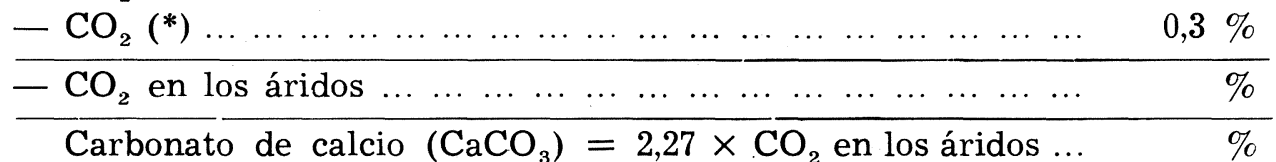

2.6.3. Total de áridos

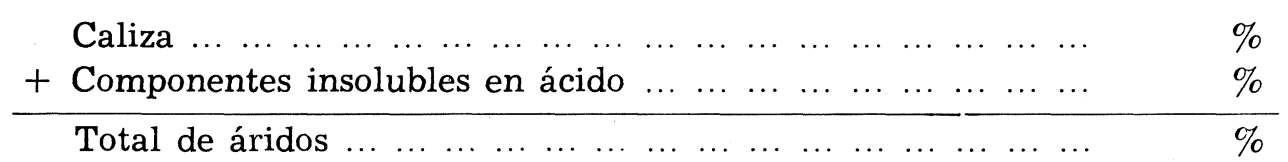

\subsubsection{Cemento}

Hormigón (secado a $105^{\circ} \mathrm{C}$ )

$100,0 \%$

$\begin{array}{lllllllllllllll}\text { - Agua combinada } & \ldots & \ldots & \ldots & \ldots & \ldots & \ldots & \ldots & \ldots & \ldots & \ldots & \ldots & \ldots & \ldots & \ldots\end{array}$

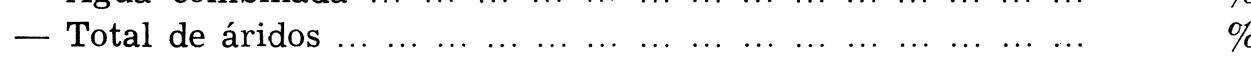

\begin{tabular}{llllllllllllllllll}
- Total de $\operatorname{aridos}$ & $\ldots$ & $\ldots$ & $\ldots$ & $\ldots$ & $\ldots$ & $\ldots$ & $\ldots$ & $\ldots$ & $\ldots$ & $\ldots$ & $\ldots$ & $\ldots$ & $\ldots$ & $\ldots$ & $\ldots$ & & $\%$ \\
\hline Cemento & $\ldots$ & $\ldots$ & $\ldots$ & $\ldots$ & $\ldots$ & $\ldots$ & $\ldots$ & $\ldots$ & $\ldots$ & $\ldots$ & $\ldots$ & $\ldots$ & $\ldots$ & $\ldots$ & $\ldots$ & $\ldots$ & $\ldots$ \\
\end{tabular}

2.6.5. Proporción de mezcla cemento : áridos (en porcentajes en peso)

$$
\text { Proporción de mezcla }=1: \frac{\text { total de áridos }(\%)}{\text { cemento }(\%)}
$$

2.6.6. Proporción de mezcla cemento : áridos : agua combinada (en porcentajes en peso) Proporción de mezcla $=1: \frac{\text { total áridos }(\%)}{\text { cemento }(\%)}: \frac{\text { agua combinada }(\%)}{\text { cemento }(\%)}$

(*) Corrección para el contenido de $\mathrm{CO}_{2}$ en el conglomerante y para la absorción de $\mathrm{CO}_{2}$ de la atmósfera durante el proceso de análisis (véase el apartado 2.1.). 


\section{2.\%. Contenido de cemento}

El contenido de cemento en $\mathrm{kg} / \mathrm{m}^{3}$ de hormigón se calcula por la densidad aparente del hormigón endurecido y por la proporción de mezcla de cemento: áridos: agua combinada, en la siguiente forma:

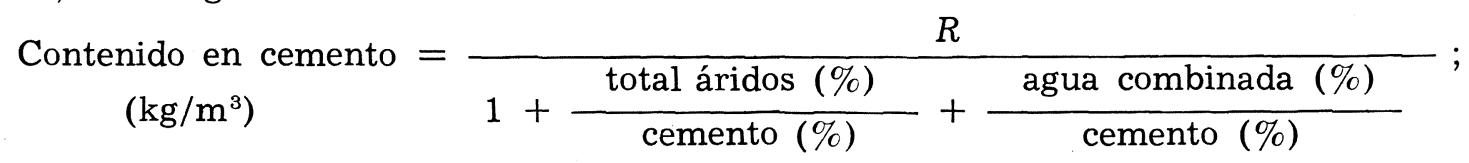

siendo $R$ la densidad aparente del hormigón.

\section{ENSAYOS DE CONTROL}

Con el fin de comprobar la exactitud del procedimiento propuesto, se elaboraron en el laboratorio de cementos y hormigones de Beckum unos cubos de $20 \mathrm{~cm}$ de lado. Los hormigones se prepararon con cemento portland y arena y grava del Rhin o del Lippe con un tamaño máximo de $30 \mathrm{~mm}$.

La arena del río Lippe contiene una parte relativamente elevada de roca carbonatada. Los hormigones presentaron una proporción de mezcla de cemento : áridos : agua = $=1,00: 6,00: 0,60$ (en peso). El contenido de cemento fue, aproximadamente, de $310 \mathrm{~kg} /$ $/ \mathrm{m}^{3}$. La curva granulométrica de los áridos se encontraba en la zona especialmente favorable de la norma DIN 1045.

El tamaño de grano ofrecía la siguiente composición:

\begin{tabular}{|c|c|c|c|c|}
\hline & $\begin{array}{r}3 \\
30\end{array}$ & $\begin{array}{r}7 \\
50\end{array}$ & & $30 \mathrm{~mm}$ \\
\hline
\end{tabular}

Los cubos se almacenaron durante 1 día envueltos en paños húmedos; más tarde, hasta el tercer día sumergidos en agua y, finalmente, al aire ambiente.

La determinación de la proporción de mezcla se efectuó, en cada uno de los cubos, al cabo de 3 y 28 días, así como al cabo de 1 año, de acuerdo con la norma DIN 52170 (a condición de que los áridos fuesen insolubles en el ácido clorhídrico), y conforme el procedimiento de corrección del $\mathrm{CaCO}_{3}$. Los resultados figuran en la tabla 1 (procedimiento según norma DIN 52170) y en la tabla 2 (procedimiento de corrección del $\mathrm{CaCO}_{3}$ ).

El procedimiento según la norma DIN 52170 arroja, en el caso del hormigón preparado con áridos del Rhin, una proporción de mezcla de 1:6,4, lo que se aproxima en su magnitud a la composición real de 1,00:6,00. En el hormigón con áridos del río Lippe, el resultado fue, según era de esperar, de 1:1,4, es decir, una proporción de mezcla totalmente inadecuada.

T A B L A 1

Proporción de mezcla de hormigones determinada según la norma DIN 52170

\begin{tabular}{|c|c|c|c|c|c|c|}
\hline \multirow{2}{*}{ Análisis } & \multicolumn{3}{|c|}{ Aridos del Rhin } & \multicolumn{3}{|c|}{ Aridos del Lippe } \\
\hline & 3 días & 28 días & 1 año & 3 días & 28 días & 1 año \\
\hline Pérdida por calcinación & 3,3 & 3,9 & 3,6 & 17,3 & 19,8 & 19,7 \\
\hline Residuo insoluble & 83,7 & 83,1 & 83,3 & 48,0 & 47,3 & 45,8 \\
\hline Cemento & 13,0 & 13,0 & 13,1 & 34,7 & 32,9 & 34,5 \\
\hline $\begin{array}{l}\text { Proporción de mezcla } \\
\text { Cemento : áridos }\end{array}$ & $1: 6,4$ & $1: 6,4$ & $1: 6,4$ & $1: 1,4$ & $1: 1,4$ & $1: 1,3$ \\
\hline
\end{tabular}


T A B L A 2

Proporción de mezcla de hormigones, determinada por el procedimiento con corrección $\operatorname{del} \mathrm{CaCO}_{3}$

\begin{tabular}{|c|c|c|c|c|c|c|}
\hline \multirow{2}{*}{ Análisis } & \multicolumn{3}{|c|}{ Aridos del Rhin } & \multicolumn{3}{|c|}{ Aridos del Lippe } \\
\hline & 3 días & 28 días & 1 año & 3 días & 28 días & 1 año \\
\hline Pérdida por calcinación & 3,3 & 3,9 & 3,6 & 18,3 & 19,8 & 19,7 \\
\hline Anhidrido carbónico & 0,5 & 0,7 & 0,8 & 15,5 & 16,6 & 16,6 \\
\hline Agua combinada & 2,8 & 3,2 & 2,8 & 2,8 & 3,2 & 3,1 \\
\hline Caliza $\left(\mathrm{CaCO}_{3}\right)$ & 0,5 & 0,9 & 1,1 & 34,5 & 37,0 & 37,0 \\
\hline Residuo insoluble en ácido & 82,5 & 81,8 & 83,3 & 49,2 & 46,1 & 45,8 \\
\hline Aridos & 83,0 & 82,7 & 84,4 & 83,7 & 83,1 & 82,8 \\
\hline Cemento & 14,2 & 14,1 & 12,8 & 13,5 & 13,7 & 14,1 \\
\hline $\begin{array}{l}\text { Proporción de mezcla } \\
\text { Cemento : áridos }\end{array}$ & $1: 5,8$ & $1: 5,9$ & $1: 6,6$ & $1: 6,2$ & $1: 6,1$ & $1: 5,9$ \\
\hline $\begin{array}{l}\text { Proporción de mezcla } \\
\text { Cemento : áridos : agua com- } \\
\text { binada }\end{array}$ & $\begin{array}{r}1: 5,8 \\
: 0,2\end{array}$ & $\begin{array}{r}1: 5,9 \\
: 0,2\end{array}$ & $\begin{array}{r}1: 6,6 \\
: 0,2\end{array}$ & $\begin{array}{r}1: 6,2 \\
: 0.2\end{array}$ & $\begin{array}{r}1: 6,1 \\
: 0,2\end{array}$ & $\begin{array}{r}1: 5,9 \\
: 0,2\end{array}$ \\
\hline $\begin{array}{l}\text { Densidad aparente del hor- } \\
\text { migón endurecido }\left(\mathrm{kg} / \mathrm{m}^{3}\right)\end{array}$ & 2.250 & 2.290 & 2.320 & 2.270 & 2.290 & 2.260 \\
\hline Contenido de cemento $\left(\mathrm{kg} / \mathrm{m}^{3}\right)$ & 320 & 322 & 298 & 306 & 312 & 318 \\
\hline
\end{tabular}

En el procedimiento con corrección del $\mathrm{CaCO}_{3}$ se efectuó también un cálculo del contenido de cemento, lo que resultó innecesario con el procedimiento según norma DIN 52170 , debido a las notables variaciones en el hormigón con áridos del río Lippe.

El procedimiento con la corrección de $\mathrm{CaCO}_{3}$ muestra, tanto con los áridos del Rhin (valor medio 1:6,1) como con los áridos del Lippe (valor medio 1:6,1), una coincidencia satisfactoria. También los contenidos de cemento se aproximan suficientemente al contenido real del mismo $\left(310 \mathrm{~kg} / \mathrm{m}^{3}\right)$.

\section{RESUMEN Y PERSPECTIVAS}

Para la determinación "a posteriori" del contenido de cemento en el hormigón, que contenga áridos solubles en ácidos, y para cuando no se dispone de áridos aisladamente para análisis adicionales, se propone un procedimiento de ensayo con una corrección del contenido de dióxido de carbono. Los análisis practicados en ciertos hormigones de laboratorio han demostrado que este procedimiento permite una determinación de la proporción de mezcla y un cálculo del contenido de cemento con una exactitud de, por lo menos, $\pm 10 \%$. De este modo puede determinarse también la proporción de mezcla del hormigón, en los casos en que falla el procedimiento usado hasta el presente, conforme la norma DIN 52170.

El método propuesto emplea también hormigones y morteros carbonatados. De todos modos deben hacerse investigaciones sobre la fijación del dióxido de carbono sobre hormigones y morteros.

Los procedimientos con "moléculas-guía" o "elementos-guía" pueden aplicarse también, en ciertas circunstancias, a otros áridos (por ejemplo, pómez, áridos ligeros, amianto y similares) o a conglomerantes con elevada proporción de componentes insolubles en ácido clorhídrico (cementos puzolánicos, cementos con adiciones). En la actualidad se están llevando a cabo esta clase de análisis. 